\title{
UJI EKSPERIMENTAL GESER INTERFACE SUBSTRATE DAN TOPPING DENGAN VARIASI KEKUATAN TEKAN PADA LAPIS TOPPING
}

\author{
Indah Nurrahman ${ }^{1}$ \\ ${ }^{1}$ Jurusan Pendidikan Teknik Sipil dan Perencanaan, Fakultas Teknik, Universitas Negeri Yogyakarta \\ Email: indah_nur@gmail.com
}

\begin{abstract}
The study aims to: determine the shear strength of concrete connection with applying compressive strength variations plans on topping layer. Extra toppings on a substrate made 28 days (the concrete substrate) and shear test connection 56 days of age (age 28 days connection). The type of concrete used is normal concrete where the connection does not roughened surface and without addictive substances. The study was conducted using laboratory experiments. This study uses the compressive strength of concrete plans substrate $20 \mathrm{MPa}$ (NCS20) and compressive strength of concrete plans topping is $20 \mathrm{MPa}$ (NCT20), $25 \mathrm{MPa}$ (NCT25) and $30 \mathrm{MPa}$ (NCT30). The test object cuboid with dimensions of $20 \times 20 \times 20 \mathrm{~cm}$. In the concrete susbtrate has a thickness of $12.5 \mathrm{~cm}$ and for concrete topping with a thickness of $7.5 \mathrm{~cm}$. Each specimen consists of 3 specimens with a total of 9 specimens. Data analysis using quantitative descriptive. The results of the study obtained compressive strength in the sample substrate with a mean NCCS20 notation is $18.51 \mathrm{MPa}$. Concrete topping cylindrical samples with notation NCCT20, NCCT25, and NCCT30 obtained a mean compressive strength is $22.21 \mathrm{MPa}, 24.39 \mathrm{MPa}$ and $30.93 \mathrm{MPa}$. Shear strength test results NCST20-20 connection with the notation, NCST20-25, and NCST20-30 ie $0.44 \mathrm{MPa}, 0.45 \mathrm{MPa}$ and $0.3 \mathrm{MPa}$. Value shear test connection is influenced by several factors, such as the connection surface texture, hydration process, aggregate functions, compressive strength, porosity of concrete, slump value and watertight.
\end{abstract}

Keywords: shear strength of the connection, substrate, topping

\begin{abstract}
ABSTRAK
Kajian dilakukan untuk mengetahui kuat geser sambungan beton dengan menerapkan variasi kekuatan tekan rencana pada lapis topping. Penambahan topping pada substrate dilakukan umur 28 hari (umur beton substrate) dan uji geser sambungan umur 56 hari (umur sambungan 28 hari). Jenis beton yang digunakan adalah beton normal dimana permukaan sambungannya tidak dikasarkan dan tanpa bahan zat adiktif. Kajian dilakukan dengan metode eksperimen di laboratorium. Kajian ini menggunakan kuat tekan rencana beton substrate 20 MPa (NCS20) dan kuat tekan rencana beton topping yaitu $20 \mathrm{MPa}$ (NCT20), $25 \mathrm{MPa}$ (NCT25), dan $30 \mathrm{MPa}$ (NCT30). Benda uji berbentuk kubus dengan dimensi $20 \times 20 \times 20 \mathrm{~cm}$. Pada bagian beton susbtrate memiliki ketebalan $12,5 \mathrm{~cm}$ dan untuk beton topping dengan ketebalan 7,5 cm. Setiap spesimen berjumlah 3 buah benda uji dengan jumlah keseluruhan 9 buah benda uji. Analisis data menggunakan deskritif kuantitatif. Hasil dari kajian didapat kuat tekan pada sampel substrate dengan notasi NCCS20 rerata yaitu 18,51 MPa. Beton silinder sampel topping dengan notasi NCCT20, NCCT25, dan NCCT30 didapat kuat tekan rerata yaitu 22,21 MPa, 24,39 MPa dan 30,93 MPa. Hasil uji kuat geser sambungan dengan notasi NCST20-20, NCST2025, dan NCST20-30 yaitu 0,44 MPa, 0,45 MPa dan 0,3 MPa. Nilai uji geser sambungan dipengaruhi oleh beberapa faktor, seperti tekstur permukaan sambungan, proses hidrasi, fungsi agregat, kuat tekan, porositas beton, nilai slump dan kedap air
\end{abstract}

Kata kunci: kuat geser sambungan, substrate, topping 


\section{PENDAHULUAN}

Pemilihan bahan untuk infrastruktur menjadi hal utama dengan menyesuaikan fungsi dan kondisi lingkungan, salah satu bahan yang sering dipakai ialah beton. Beton merupakan campuran yang terdiri dari pasir, kerikil, semen, dan air. Pemilihan menggunakan beton dikarenakan bahan yang mudah didapat, harga yang terjangkau, perawatan mudah dilakukan, tahan terhadap suhu yang tinggi, memiliki kuat tekan yang tinggi, mudah dalam pembuatan, dan dapat dibentuk sesuai keinginan. Untuk mendapatkan hasil beton yang baik sangat ditentukan dari perancangan campuran, pembuatan campuran dan pengerjaan saat dilapangan. Untuk memiliki nilai tekan yang tinggi perlunya dilakukan perawatan dan pengujian sesuai. Untuk perawatan dapat dilakukan dengan beberapa cara, seperti menempatkan beton di dalam ruangan yang lembab, menempatkan beton di atas genangan air, meletakan beton di dalam air, menyelimuti beton dengan karung basah, dan menyirami permukaan beton setiap saat secara terus-menerus. Sementara untuk pengujian uji tekan biasa dilakukan dengan menggunakan beton silinder dan untuk pengujian kuat lentur menggunakan balok (Tjokrodimuljo, 2007).

Seiring berjalannya waktu banyak ditemukannya permasalahan pada beton. Dengan kemajuan teknologi begitu banyak cara untuk menangani masalah-masalah yang terjadi pada beton. Keropos merupakan salah satu masalah yang sering dihadapi, dengan itu perlunya dilakukan perbaikan. Perbaikan beton biasanya termasuk menghilangkan beton yang tidak kokoh dan diganti dengan material baru untuk perbaikan atau diberikan lapisan material baru. Salah satu kunci yang dibutuhkan dalam berbagai jenis sistem perbaikan adalah untuk mendapatkan kekuatan sambungan yang cukup memadai antara beton yang telah ada dengan lapisan baru selama jangka waktu umur rencana beton. Beberapa tes telah ada untuk mengukur kekuatan sambungan. Pengukuran kekuatan sambungan sangat bergantung terhadap metode uji dengan perkembangan dari bahan adiktif, perencana selalu dihadapkan dengan pemilihan kekuatan sambungan dari keterangan- keterangan data yang disajikan oleh pabrikan. Berdasarkan dari penggunaan metode uji, pelaporan kekuatan sambungan mungkin menaksir terlalu tinggi kekuatan sebenarnya dari produk untuk penggunaan yang diinginkan. Oleh karena itu masih perlu dilakukan pembandingan pengujian yang berbeda dalam mengukur kekuatan sambungan dan untuk membuat hubungan diantara nilai yang didapatkan dari setiap pengujian (Momayez, 2005).

Struktur beton diperbaiki atau diperkuat dengan menambahkan lapisan beton baru. Jacketing beton adalah teknik penyebaran dimana sebagian atau seluruhnya balok dan kolom diberi lapisan beton baru. Contohnya seperti deck jembatan dan lempengan bangunan diperkuat dengan meningkatkan ketebalan beton. Meningkatkan kekuatan ikatan antara lapisan beton dapat dilakukan dengan cara mengkasarkan permukaan sambungan beton substrate, apabila beton substrate tidak mengalami kerusakan (permukaan halus). Pada beton substrate tidak memperhitungkan terjadinya penyusutan dan langsung ditambah lapisan beton topping. Diferensial kekakuan dengan modulus young diantara kedua lapisan beton tidak ditangani dengan baik, hal tersebut dapat menimbulkan tambahan tekanan pada permukaan sambungan. Dengan itu perlunya perbaikan untuk meningkatkan beton dalam ketepatan prediksi kekuatan 
longitudinal pada permukaan sambungan beton lama dan beton baru (Santos dan Julio, 2009).

Selain perbaikan pada struktur dengan penambahan beton topping dapat juga memperkuat struktur seperti penambahan topping pada deck jembatan. Dalam kajian Sukrawa, dkk (2011) banyak jembatan mengalami kerusakan terutama pada pelat lantai kendaraan, seperti keretakan akibat lentur dan geser yang pada akhirnya membentuk lubang. Mempertebal pelat jembatan yang sudah ada memerlukan metode tertentu. Aksi komposit antara beton lama dan overlay dapat diperoleh dengan pemakaian boding agent, penambahan penghubung geser, dan persiapan permukaan pelat lama berupa tekstur. Perkuatan pelat dengan topping mampu meningkatkan kekakuan dan kekuatan pelat secara meyakinkan. Peningkatan kekuatan minimum sebesar $45 \%$ diamati pada umur overlay 3 hari dengan peningkatan kekakuan sebesar $100 \%$.

Penyambungan antara lapisan beton yang dilakukan dalam pengujian untuk menemukan nilai kekuatan beton itu sendiri terhadap gaya geser yang terjadi. Maka dilakukan kajian dengan membuat beberapa benda uji dengan variasi kuat tekan rencana yang berbeda pada lapis topping, agar dapat membandingkan hasil nilai yang didapat. Dalam kajian ini dibuat benda uji berbentuk kubus dengan pengecoran pertama memiliki kuat tekan rencana yaitu $20 \mathrm{MPa}$ dan diberi topping dengan kuat tekan rencana yang bevariasi yaitu $20 \mathrm{MPa}, 25 \mathrm{MP}$, dan 30 $\mathrm{MPa}$. Pada umumnya nilai kuat tekan rencana pada substrate merupakan batasan minimal nilai kuat tekan rencana pada beton topping. Kajian ini memakai kuat tekan rencana $20 \mathrm{MPa}, 25 \mathrm{MPa}$ dan $30 \mathrm{MPa}$ karena rentang nilai yang biasa digunakan pada kajian sebelumnya berkisar antara $20 \mathrm{MPa}$ sampai $30 \mathrm{MPa}$. Sama halnya dengan beton topping pemilihan kuat tekan rencana $20 \mathrm{MPa}$ pada beton substrate kuat tekan minimal beton perstruktural $20 \mathrm{MPa}$.

Pada benda uji permukaan sambungan tidak dikasarkan, hal tersebut dilakukan untuk mengetahui kekuatan geser dengan permukaan sambungan tanpa pengkasaran. Pengujian pada sambungan antara beton substrate dan beton topping dipilih uji geser karena dengan penambahan beton topping secara tegak lurus pada sambungan menimbulkan tegangan geser yang diakibatkan oleh adanya beban/gaya yang sejajar dengan potongan. Sambungan antara beton merupakan bagian terlemah terhadap penerimaan gaya geser, dengan adanya gaya geser sangat mudah terjadi retak dan mengakibatkan terjadinya patahan pada sambungan.

Metode uji untuk benda uji menggunakan metode b.i surface shear test. Kelebihan dari metode b.i surface shear test ini yaitu dalam aplikasi pengujiannya mudah dilakukan, distribusi yang respentatif, dan b.i surface shear test dianalisis dengan asumsi beban yang bekerja berupa deformasi yang terjadi merata pada salah satu sisi bidang tumpuan. Hasil yang lebih respentatif ditandai dengan komponen gaya normal tegak lusur bidang geser yang relatif kecil, dan distribusi tegangan geser yang lebih merata.

Pada kajian ini terdapat beberapa tujuan yang akan dicapai. Adapun tujuan kajian ini adalah sebagai berikut: (1) Mengetahui kuat tekan beton silinder untuk sampel substrate dan topping pada umur 28 hari. (2) Mengetahui kuat geser sambungan/interface dengan variasi kuat tekan rencana pada lapis topping. (3) 
Mengetahui faktor apa saja yang memepengaruhi nilai kuat geser langsung pada sambungan substrate dan topping.

Beton merupakan campuran dari agregat halus dan agregat kasar (kerikil, batu pecah atau jenis agregat lainnya) dengan semen, yang dipersatukan oleh air dalam perbandingan tertentu. Beton juga dapat didefinisikan sebagai bahan bangunan dan kontruksi yang sifat-sifatnya dapat ditentukan terlebih dahulu dengan mengadakan perencanaan dan pengawasan yang teliti terhadap bahanbahan lain (agregat, semen dan air). Proses pengerasan terjadi karena adanya reaksi kimia antara air dengan semen yang terus berlangsung dari waktu ke waktu. Hal ini menyebabkan kekerasan beton terus bertambah sejalan dengan waktu. Rongga pada partikel yang besar (agregat kasar) diisi oleh agrgat halus dan rongga diantara agregat halus akan diisi oleh pasta (campuran air dengan semen) yang juga berfungsi sebagai bahan pengikat (Samekto \& Rahmadiyanto, 2001). Semen Portland akan terus bereaksi dengan air saat pengikatan terjadi. Setelah 24 jam pada temperatur $30 \%-40 \%$ semen biasanya mengalami proses hidrasi, pembentukan lapisan penutup dengan bertambahnya kepadatan dan ketebalan yang melapisi partikelnya. Hidrasi partikel klinker yang besar secara parsial dan keseluruhan akan membentuk beton. Siklus proses pembentukan beton dari saat mulai mengeras sampai dengan beton berumur 90 hari (Mulyono, 2005).

Beton merupakan fungsi dari bahan penyusunnya yang terdiri dari bahan semen hidrolik, agregat kasar, agregat halus, air dan bahan tambah. Beton dapat juga dicampur dengan bahan lain sesuai dengan perilaku yang akan diberikan terhadap beton tersebut, misalnya beton pra-tekan atau beton pra-tenggang, beton pra-cetak. Beton juga dapat digunakan untuk struktur yang memerlukan bahan struktur yang ringan, misalnya beton ringan struktural yaitu beton yang mengandung agregat ringan dan mempunyai massa kering udara yang sesuai dengan syarat (Mulyono, 2005).

Pada umumnya beton terdiri dari kurang lebih 15\% semen, $8 \%$ air, 3\% udara selebihnya pasir dan kerikil. Campuran tersebut setelah mengeras mempunyai sifat yang berbeda-beda, tergantung pada cara pembuatannya. Perbandingan campuran, cara mencapur, cara mengangkut, cara mencetak, cara memadatkan, cara merawat dan sebagainya akan mempengaruhi sifat-sifat beton. Sifat-sifat tersebut juga relatif ditinjau dari sudut pemakaian beton, hal terpenting yaitu beton harus memiliki sifatsifat yang sesuai dengan tujuan pemakaian beton (Samekto \& Rahmadiyanto, 2001).

Kemampuan dikerjakan atau workability mempunyai maksud bahwa bahan-bahan beton setelah diaduk bersama menghasilkan adukan yang bersifat sedemikian rupa sehingga adukan mudah diangkut, dituang/dicetak, dan dipadatkan. Sifat tahan lama pada beton merupakan sifat dimana beton tahan terhadap pengaruh luar selama pemakaian. Beton mempunyai kecenderungan mengandung rongga-rongga yang diakibatkan oleh adanya gelembung udara yang terbentuk selama atau sesudah pencetakan selesai, atau ruangan yang saat mengerjakan (selesai dikerjakan) mengandung air. Bila semakin banyak rongga pada beton maka masuknya air makin besar, dan kemungkinan terbentuknya pipa kapiler makin besar. Sifat kedap air pada beton terutama didapat jika didalam beton itu tidak 
terdapat pipa kapiler yang menerus, karena dengan adanya pipa kapiler ini air akan mengalir menembus beton. Untuk mengurangi kemungkinan masuknya air kedalam beton, beton harus dibuat sepadat mungkin. Untuk mendapatkan beton yang kedap air. Kekuatan beton merupakan menjadi sifat utama yang umumnya harus dimiliki oleh beton, sebab beton yang tidak cukup kekuatannya menurut kebutuhannya menjadi tidak berguna. Adapun yang mempengaruhi kekuatan beton seperti faktor air semen dan kepadatan.

Pada kontruksi beton mutu tinggi, dituntut untuk dapat merancang komposisi campuran beton yang tepat. Pembuatan beton dengan menggunkan perbandingan volume yang biasa dipakai 1 semen : 2 pasir : 3 kerikil untuk beton biasa dan untuk campuran 1 semen : 11/2 pasir : 21/2 kerikil untuk beton kedap air rupanya sudah kurang memuaskan lagi, karena dapat menghasilkan kuat desak beton yang sangat beragam (bervariasi). Perencanaan aduk beton dimaksud untuk mendapatkan beton yang sebaik-baiknya, antara lain untuk mendapatkan: Kuat desak yang tinggi sesuai dengan perencanaan, mudah dikerjakan, tahan lama, tahan aus.

Sementara itu, metode pencampuran dari beton diperlukan untuk mendapatkan kelecekan yang baik sehingga beton dapat dengan mudah dikerjakan. Kemudahan pekerjaan atau workability pada pekerjaan beton didefinisikan sebagai kemudahan untuk dikerjakan, dituangkan dan dipadatkan serta dibentuk dalam acuan (Ilsay, 1942:224). Kemudahan pengerjaan ini diindikasikan melalui slump test; semakin tinggi nilai slump, semakin mudah untuk dikerjakan. Namun demikin nilai dari slump ini harus dibatasi. Nilai slump yang terlalu tinggi akan membuat beton kropos setelah mengeras karena air yang terjebak dalamnya menguap. Metode pengadukan atau pencampuran beton akan menentukan sifat kekuatan dari beton, walaupun rencana campuran baik dan syarat mutu bahan telah terpenuhi. Pengadukan yang tidak baik akan menyebabkan terjadinya bleeding, dan halhal yang tidak dikehendaki.

\section{METODE}

Metode yang digunakan dalam kajian ini adalah eksperimen, yaitu kajian dengan beberapa sampel benda uji yang bertujuan untuk menyelidiki hubungan sebab akibat antara satu dengan yang lain dan membandingkan hasilnya sehingga menjadi sebuah inovasi. Kajian ini dilakukan di labolatorium Bahan Bangunan Fakultas Teknik Universitas Negeri Yogyakarta (FT UNY). Benda uji yang dibuat dalam kajian ini adalah beton normal berbentuk kubus dengan kuat tekan rencana pada bagian substrate $20 \mathrm{MPa}$ serta pada bagian topping $20 \mathrm{MPa}, 25$ $\mathrm{MPa}$, dan $30 \mathrm{Mpa}$. Ukuran benda uji tersebut adalah $20 \times 20 \times 20 \mathrm{~cm}$ serta beton silinder dengan diameter $15 \mathrm{~cm}$ dan tinggi $30 \mathrm{~cm}$.

Kajian dilakukan secara bertahap, yaitu terdiri dari pengujian material, perancangan campuran, pelaksanaan pengecoran, dan pengujian. Dari serangkaian tahapan tersebut akan dilakukan pengukuran pada benda uji dari hasilnya akan diperoleh data-data yang digunakan untuk analisis lebih lanjut sebagai data primer. Metode kajian yang diterapkan dengan melalui eksperimen laboratorium, maka sebagai landasan penarikan kesimpulan digunakan berbagai variabel kajian. Variabel kajian adalah segala sesuatu yang ditetapkan oleh peneliti untuk dipelajari sehingga didapatkan sebuah informasi untuk diambil sebuah kesimpulan. 
Variabel bebas adalah variabel yang mempengaruhi timbulnya variabel terikat. Variabel bebas yang dimaksudkan dalam kajian ini adalah penetapan variasi kuat tekan rencana pada lapis topping dengan kuat tekan rencana $20 \mathrm{MPa}, 25 \mathrm{MPa}$, dan $30 \mathrm{MPa}$. Sementara itu, variabel terikat adalah variabel yang di pengaruhi atau yang menjadi akibat, karena adanya variabel bebas. Variabel terikat dalam pada kajian ini adalah kuat tekan beton silinder (sampel substrate dan topping) dan kuat geser yang terdiri dari substrate ditambah topping. Sedangkan variabel kontrol adalah variabel konstan yang digunakan untuk membandingkan variabel lain. Faktor-faktor yang dapat mempengaruhi kuat tekan dan kuat geser sambungan beton antara lain adalah tipe semen, umur sambungan, cara perawatan benda uji, ukuran butir maksimum agregat dan kondisi permukaan sambungan.

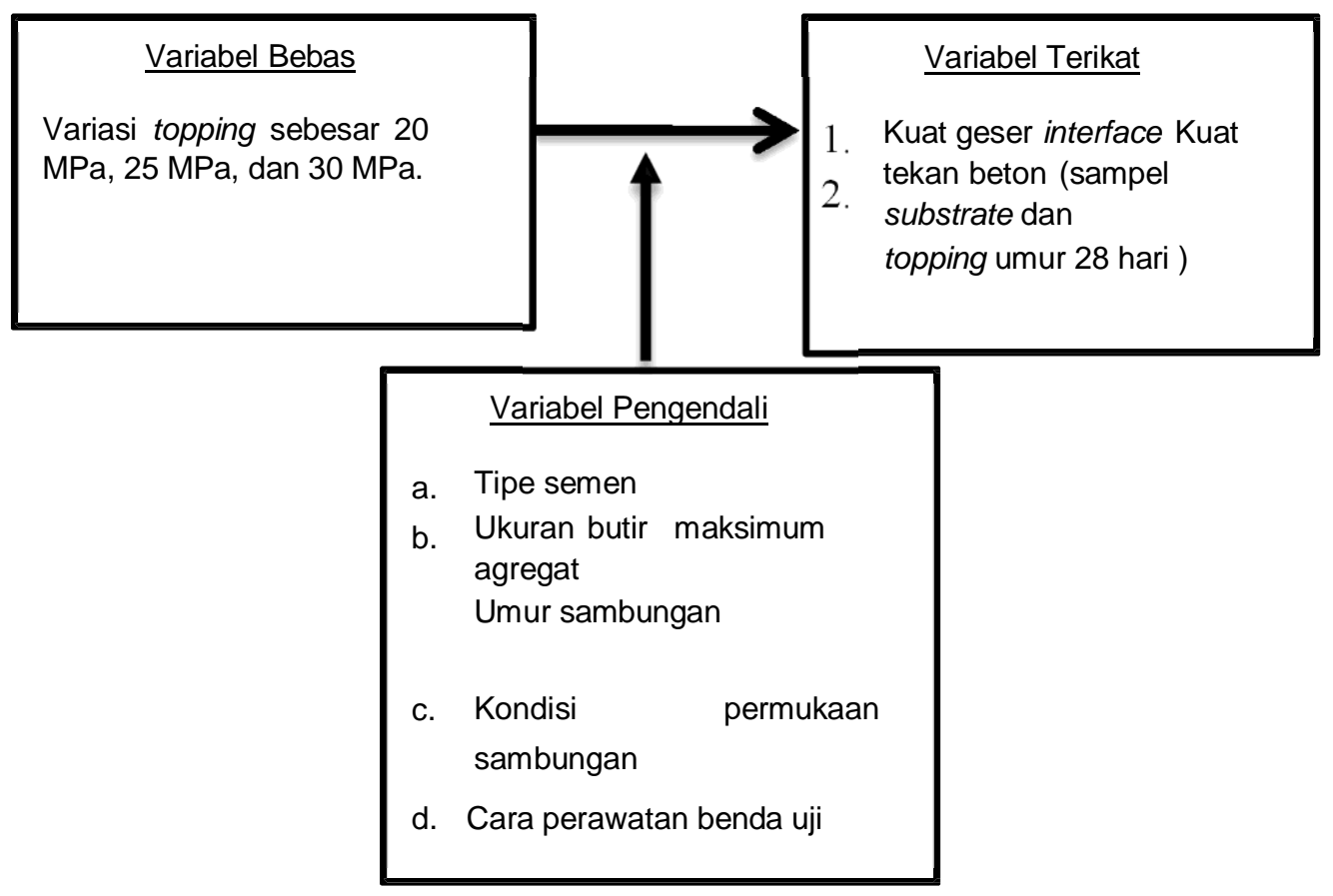

Gambar 1. Hubungan antara variabel

Guna mendapatkan hasil dalam proyek akhir ini diperlukan berbagai bahan dan alat. Bahan yang digunakan dalam proyek ini antara lain: (1) Agregat halus, agregat halus berupa pasir alami yang diperoleh dari kabupaten Sleman. Menurut SNI 026820-2002, agregat halus adalah agregat dengan besar butir maksimum 4,75 mm. Agregat halus yang digunakan adalah pasir alami yang berasal dari sungai progo.
(2) Agregat kasar, agregat kasar adalah agregat dengan besar butir minimum 4,75 $\mathrm{mm}$. Metode ini digunakan sebagai acuan untuk menentukan berat jenis curah, berat jenis kering permukaan jenuh, berat jenis semu, dan penyerapan dari agregat kasar. (3) Semen, dalam eksperimen ini semen yang digunakan adalah semen Gresik dengan berat tiap sak adalah $40 \mathrm{~kg}$, dimana butirannya halus dan tidak terdapat 
penggumpalan., semen ini termasuk dalam Pozzolan Portland Cemen (PPC), yaitu digunakan untuk semua tujuan pembuatan adukan beton. (4) Air, air diperlukan dalam pembuatan mortar maupun beton untuk memicu proses kimiawi semen, membasahi agregat, dan memberikan kemudahan dalam pekerjaan pengadukan. Air yang dapat diminum umumnya dapat digunakan sebagai campuran mortar. Air yang mengandung senyawa-senyawa yang berbahaya, tercemar garam, minyak, gula, atau bahan kimia lainnya, bila dipakai dalam campuran mortar akan menurunkan kualitas, dan bahkan dapat mengubah sifat-sifat mortar yang dihasilkan (Mulyono, 2005). Air yang digunakan diperoleh dari laboratorium Bahan Bangunan FT UNY. (5) Oli, dalam kajian ini oli digunakan sebagai bahan pendukung kajian seperti belerang. Berdasarkan SNI 6369-2008:11 tentang pembuatan capping untuk benda uji silinder. Oli digunakan sebagai pelumas pelat capping agar benda uji mudah untuk dilepas. Selain itu oli juga digunakan sebagai pelumas bekisting. (6) Belerang, digunakan untuk bahan pembuat capping. Untuk kuat tekan beton kurang dari 35 Mpa maka capping harus dibiarkan mengeras selama 2 jam sebelum pengujian beton dan untuk kuat tekan beton lebih dari $35 \mathrm{Mpa}$ maka capping dibiarkan mengeras 16 jam sebelum pengujian.

Sementara itu, alat yang digunakan dalam proyek akhir ini antara lain: (1) Oven, yang digunakan harus dapat memanaskan sampai temperatur 110 derajat celcius. Oven yang dipakai yaitu type UN 110 diproduksi oleh jerman dan memilki kapasitas suhu sampai $300^{\circ} \mathrm{C}$. (2) Pengaduk beton atau mixer, berupa drum pengaduk dengan tenaga penggerak, wadah adukan yang dapat berjungkit, atau wadah yang berputar dengan baik atau wadah dengan pendayung yang berputar. Alat ini harus dapat mengaduk secara langsung sesuai dengan banyaknya adukan dengan slump yang diperlukan. Hal ini dimaksudkan agar campuran mortar lebih homogen. Kapasitas pada mesin aduk yaitu $0,25 \mathrm{~m}^{3}$. (3) Bekisting, yaitu cetakan yang digunakan dalam kajian dengan ukuran 200x200x200 ketebalan 9 $\mathrm{mm}$ yang terbuat dari multipleks. Selain itu, terdapat pula bekisting silinder, cetakan yang digunakan dalam kajian ini untuk menguji kuat tekan yaitu cetakan berbentuk silinder dengan tinggi $300 \mathrm{~mm}$ dan diameternya $150 \mathrm{~mm}$. (4) Alat capping, tebal plat capping tidak kurang dari $6 \mathrm{~mm}$, diameter plat sekurang-kurangnya harus $25 \mathrm{~mm}$ lebih besar dari diameter benda uji dan kemiringan permukaan capping tidak boleh lebih dari $0.05 \mathrm{~mm}$ untuk diameter silinder $152 \mathrm{~mm}$. Selain itu pelat capping harus halus, tidak ada retakan maupun goresan. Fungsi dari alat capping sendiri adalah untuk mencetak belerang cair agar dapat meratakan permukaan benda uji silinder. Alat pelurus digunakan bersamaan dengan plat capping agar benda uji silinder tegak lurus. Dibawah ini adalah gambar dari alat capping. (5) Kerucut abrams, yaitu kerucut terpancung yang digunakan untuk menguji slump maupun slump flow pada saat beton styrofoam dan mortar dalam kondisi segar.

Kerucut abrams harus terbuat dari logam yang tidak lengket dan tidak bereaksi dengan pasta semen. Kerucut abrams harus mempunyai diameter dasar $200 \mathrm{~mm}$, $100 \mathrm{~mm}$ dan tinggi $300 \mathrm{~mm}$. Batas toleransi ukuran harus dalam rentang 3.2 $\mathrm{mm}$. Bagian dalam kerucut abrams harus licin, halus dan bebas kotoran yaitu berupa mortar yang menempel. Selain itu kerucut abrams harus dilengkapi dengan injakan kaki dan pegangan. Untuk slump flow sebaran yang direncanakan antara $50 \mathrm{~mm}$ sampai $75 \mathrm{~mm}$, karena apabila sebaran dari slump flow sudah lebih dari $75 \mathrm{~mm}$ maka telah terjadi bleeding. (6) Konik, berupa kerucut berpancung yang digunakan untuk pengujian SSD dari agregat halus. Alat pengujian pasir terdiri 
Uji Eksperimental Geser ... (Indah/ hal 180-195)

dari 2 alat yaitu penumbuk dan corong. Penumbuk merupakan batang baja diameter $16 \mathrm{~mm}$ dengan bagian bawahnya rata. (7) Mesin uji tekan, digunakan untuk uji tekan adalah ELE dengan kapasitas 200 ton. Selain itu, terdapat pula peralatan kecil yang biasa digunakan dalam proyek pengujian bahan bangunan, diantaranya cetok, kuas, meteran, bak rendam, jangka sorong, timbangan, gelas ukur, ayakan, kompor listrik, dan cawan.

Pengujian yang dilakukan yaitu uji tekan untuk beton silinder dan uji geser untuk beton kubus. Beton dalam kajian ini menggunakan beton normal. Berikut jumlah sampel yang dibutuhkan dalam kajian ini.

Tabel 1. Jumlah Sampel Benda Uji Beton Silinder

\begin{tabular}{cccc}
\hline No & Kode & $f^{\prime} \mathrm{c}(\mathrm{MPa})$ & Jumlah sampel \\
\hline 1 & $\mathrm{NCCS}_{2}$ & 20 & 3 \\
2 & $\mathrm{NCCT}_{2}$ & 20 & 3 \\
3 & $\mathrm{NCCT}_{2}$ & 25 & 3 \\
4 & $\mathrm{NCCT}_{3}$ & 30 & 3 \\
\hline
\end{tabular}

Tabel 2. Jumlah Sampel Beton Kubus

\begin{tabular}{ccccc}
\hline \multirow{2}{*}{ No } & \multirow{2}{*}{ Notasi } & \multicolumn{2}{c}{ Kuat tekan rencana (MPa) } & Jumlah sampel \\
\hline 1 & NCST20-20 & 20 & Sopping & 3 \\
2 & NCST20-25 & 20 & 20 & 3 \\
3 & NCST20-30 & 20 & 25 & 3 \\
\hline
\end{tabular}


Uji Eksperimental Geser ... (Indah/ hal 180-195)

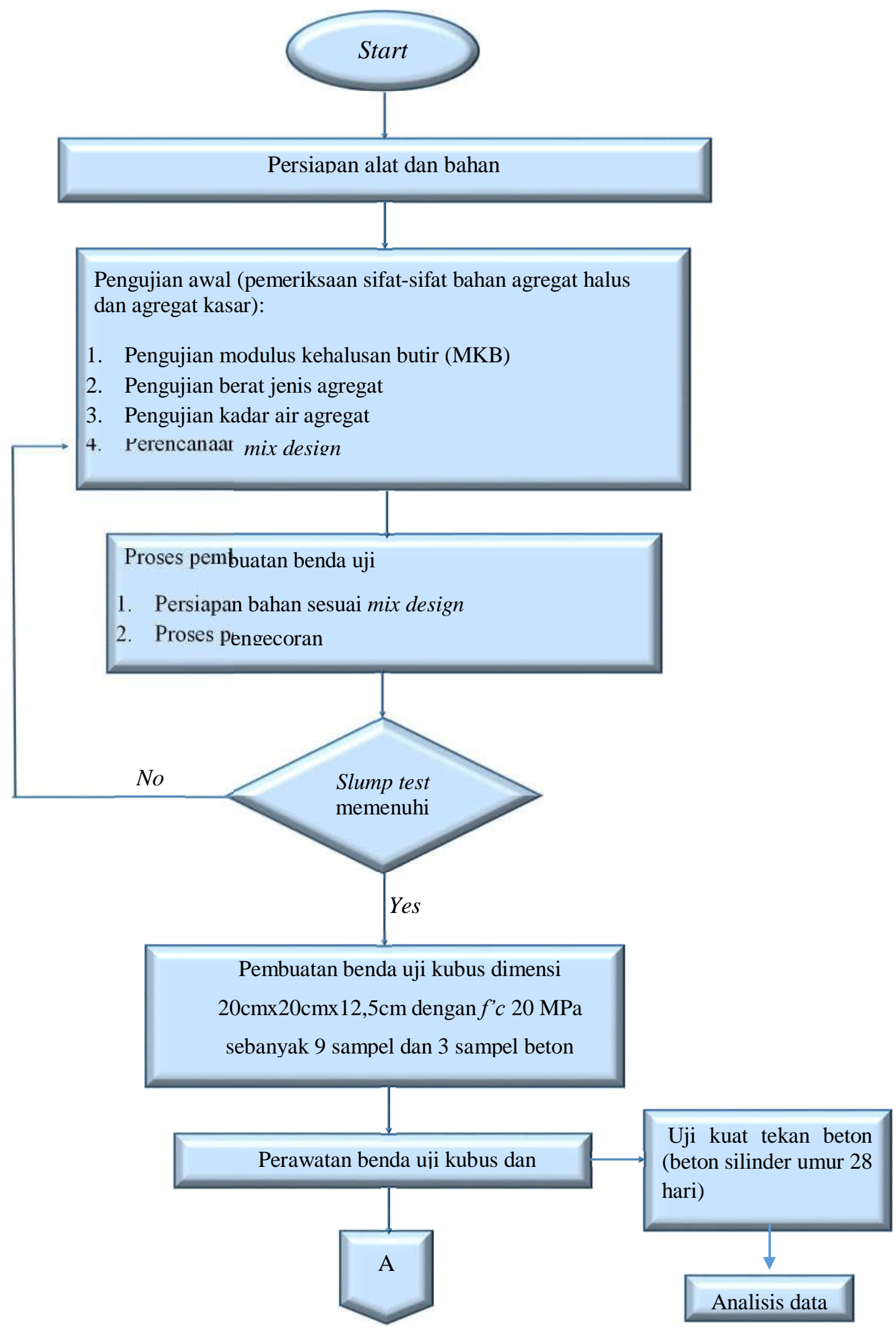

Gambar 2. Diagram alur kajian beton dengan variasi pada topping 
Uji Eksperimental Geser ... (Indah/ hal 180-195)

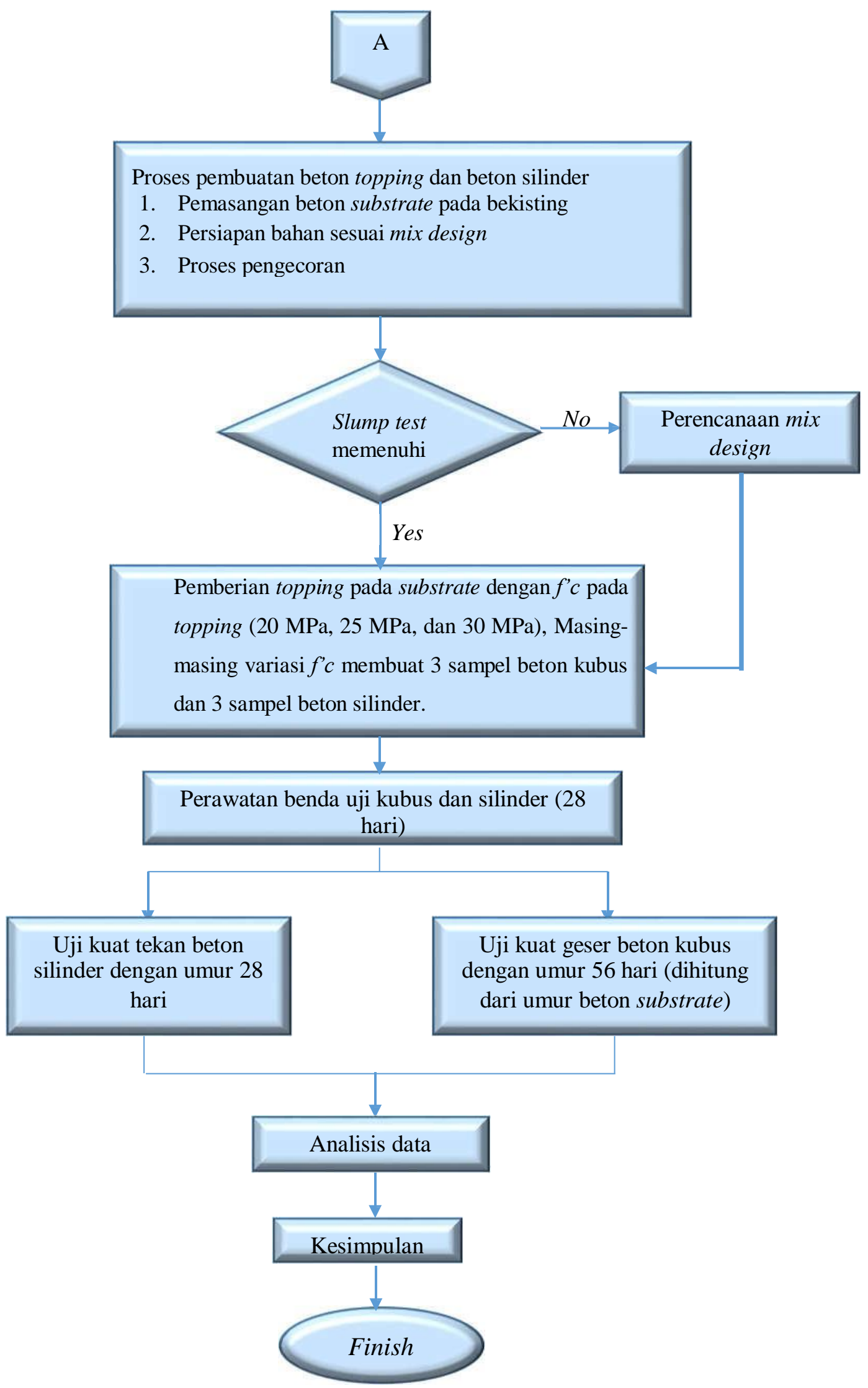

Gambar 2. Diagram alur kajian beton dengan variasi pada topping 


\section{HASIL DAN PEMBAHASAN}

Sebelum memakai bahan/material untuk membuat benda uji, perlunya menguji bahan-bahan yang akan digunakan. Pada bagian ini yang akan dibahas yaitu hasil pengujian yang dikategorikan sebagai pengujian awal untuk mendukung pengujian selanjutnya. Pengujian yang dilakukan yaitu pengujian terhadap modulus kehalusan butir, kadar air pada agregat dan berat jenis agregat.

Pengujian terhadap modulus kehalusan butir dilakukan untuk menganalisa gradasi agregat yang digunakan, yaitu berupa agregat kasar agregat halus. Untuk penentuan modulus kehalusan butir menggunakan persamaan jumlah persen kumulatif dari butir-butir agregat yang tertinggal diatas set ayakan kemudian dibagi konstanta seratus (Tjokrodimuljo, 2007).
Pengujian terhadap modulus kehalusan butir agregat kasar (kerikil) merupakan agregat yang tertahan oleh saringan nomor 4. Nilai modulus kehalusan butir dapat dikategorikan sebagai agregat kasar apabila memenuhi nilai antara 6,00 sampai 7,00 (Tjokrodimuljo,2007). Analisa terhadap modulus kehalusan butir merupakan prosedur yang wajib dilakukan karena digunakan untuk menentukan pembagian butir (gradasi) agregat halus dengan agregat kasar dengan tujuan untuk memperoleh distribusi besaran atau jumlah presentase butiran. Analisis saringan agregat ialah penentuan berat butiran agregat yang lolos dari satu set saringan. Peralatan yang digunakan meliputi timbangan, satu set saringan, oven, alat pemisah, mesin guncang saringan, talen dan alat lainnya. Benda uji yang berupa agregat, baik agregat halus (pasir) maupun agregat kasar (kerikil). Berikut hasil pengujian modulus kehalusan butir agregat kasar.

Tabel 3. Pengujian Modulus Kehalusan Butir Kerikil

\begin{tabular}{ccccc}
$\begin{array}{c}\text { Lubang } \\
\text { Ayakan }(\mathrm{mm})\end{array}$ & $\begin{array}{c}\text { Berat Tertinggal } \\
(\mathrm{gr})\end{array}$ & $\begin{array}{c}\text { Persen Tertinggal } \\
(\%)\end{array}$ & $\begin{array}{c}\text { Persen Tertinggal } \\
\text { Kumulatif }(\%)\end{array}$ & $\begin{array}{c}\text { Persen Tembus } \\
\text { Kumulatif }(\%)\end{array}$ \\
\hline 50 & 0 & 0 & 0 & 100 \\
38,1 & 0 & 0 & 0 & 100 \\
25 & 0 & 0 & 0 & 100 \\
19 & 329 & 8,23 & 8,23 & 91,77 \\
12,5 & 2331 & 58,28 & 66,51 & 33,49 \\
9,5 & 1121 & 28,03 & 94,53 & 0,46 \\
4,75 & 207 & 5,18 & 99,71 & 0,06 \\
2,36 & 8,8 & 0,22 & 99,93 & 0,03 \\
1,18 & 1,3 & 0,03 & 99,96 & 0,01 \\
0,6 & 0,83 & 0,02 & 99,98 & - \\
0,3 & 0,7 & 0,02 & 100 & - \\
0,15 & 0 & 0 & 100 & \\
$<0,15$ & - & - & - & \\
Jumlah & 3999,63 & 100 & 768,85 & \\
\hline
\end{tabular}

Pengujian terhadap modulus kehalusan butir pasir (agregat halus) adalah agregat yang lolos saringan diameter $4,75 \mathrm{~mm}$ atau saringan nomor 4 . Nilai modulus kehalusan dapat memenuhi apabila nilainya antara 1,50 sampai 3,80 (Tjokrodimuljo, 2007). Berikut hasil pengujian modulus kehalusan butir agregat halus. 
Uji Eksperimental Geser ... (Indah/ hal 180-195)

Tabel 4. Pengujian Modulus Kehalusan Butir Pasir

\begin{tabular}{cccc}
\hline Lubang Ayakan $(\mathrm{mm})$ & $\begin{array}{c}\text { Berat Tertinggal } \\
(\mathrm{gr})\end{array}$ & $\begin{array}{c}\text { Persen tertinggal } \\
(\%)\end{array}$ & $\begin{array}{c}\text { Persen tertinggal kumulatif } \\
(\%)\end{array}$ \\
\hline 9,5 & 0 & 0 & 0 \\
4,75 & 42,38 & 4,24 & 4,24 \\
2,36 & 70,5 & 7,06 & 11,31 \\
1,18 & 171,15 & 17,14 & 28,45 \\
0,6 & 354,98 & 35,55 & 64 \\
0,3 & 190,15 & 19,04 & 83,04 \\
0,15 & 149,5 & 14,97 & 98,02 \\
$<0,15$ & 19,8 & 1,98 & - \\
Jumlah & 998,46 & 100 & \\
\hline
\end{tabular}

Hasil perhitungan modulus kehalusan butir diatas telah memenuhi standar yang disyaratkan yaitu antara $1,50-3,80$.
Selanjutnya zona gradasi ditampilkan pada Tabel berikut:

Tabel 5. Zona Kehalusan Butir Agregat Halus

\begin{tabular}{cccc}
\hline Lubang Ayakan $(\mathrm{mm})$ & Batas Atas $(\%)$ & Batas Bawah $(\%)$ & Hasil Pengujian $(\%)$ \\
\hline 0,15 & 10 & 0 & 16,96 \\
0,3 & 40 & 12 & 36 \\
0,6 & 79 & 60 & 71,55 \\
1,18 & 100 & 75 & 88,69 \\
2,36 & 100 & 85 & 95,76 \\
4,75 & 100 & 90 & 100 \\
9,5 & 100 & 100 & 100 \\
\hline
\end{tabular}

Teknis untuk setiap pengujian menggunakan tiga buah sampel dimana pada masing-masing pengujian akan mendapatkan nilai berat kerikil atau pasir, volume air awal, volume air akhir, dan selanjutnya dianalisa untuk mendapatkan nilai berat jenis. Berikut hasil dari pengujian berat jenis:

Tabel 6. Pengujian Berat Jenis Kerikil dan Pasir

\begin{tabular}{ccccc}
\hline Jenis Pengujian & Spacimen & Berat $(\mathrm{gr})$ & Volume air awal $(\mathrm{ml})$ & Volume air akhir $(\mathrm{ml})$ \\
\hline Berat Jenis & 1 & 104 & 200 & 240 \\
Kerikil SSD & 2 & 101,05 & 200 & 240 \\
& 3 & 107 & 200 & 243 \\
Berat Jenis & 1 & 100,35 & 150 & 187 \\
Pasir SSD & 2 & 100,55 & 150 & 187 \\
& 3 & 100,35 & 150 & 188 \\
\hline
\end{tabular}

Pengujian kuat tekan beton dilakukan pada beton normal yang berbentuk silinder dengan dimensi yaitu tinggi $30 \mathrm{~cm}$ dan diameter $15 \mathrm{~cm}$. Pengujian dilakukan pada umur 28 hari. Dengan hasil pengujian kuat tekan beton silinder dapat dianalisa.
Analisa hasil pengujian kuat tekan untuk mengetahui kemampuan beton untuk menahan gaya tekan dalam setiap satuan luas permukaan beton. Pengujian dilakukan dengan mesin UTM (Universal Testing Machine).

Tabel 7. Nilai Uji Kuat Tekan Beton Silinder

\begin{tabular}{cccccc}
\hline \multirow{2}{*}{ Jenis Spesimen } & Spesimen & \multirow{2}{*}{ Variasi } & $\begin{array}{c}\text { Luas } \\
\left(\mathrm{mm}^{2}\right)\end{array}$ & $\begin{array}{c}\mathrm{P} \\
(\mathrm{N})\end{array}$ & $\begin{array}{c}\text { Kuat tekan } \\
\text { f'c (MPa) }\end{array}$ \\
\hline $\mathrm{NCCS}_{2}$ & 1 & & 17727,32 & 320000 & 18,05 \\
& 2 & Substrate & 18017,52 & 300000 & 16,65 \\
& 3 & & 17768,63 & 370000 & 20,82 \\
\hline
\end{tabular}


Uji Eksperimental Geser ... (Indah/ hal 180-195)

\begin{tabular}{|c|c|c|c|c|c|}
\hline \multirow[t]{2}{*}{ Jenis Spesimen } & Spesimen & \multirow[t]{5}{*}{ Variasi } & $\begin{array}{l}\text { Luas } \\
\left(\mathrm{mm}^{2}\right)\end{array}$ & $\begin{array}{l}\mathrm{P} \\
(\mathrm{N})\end{array}$ & 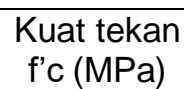 \\
\hline & rerata & & & & 18,51 \\
\hline \multirow[t]{3}{*}{$\mathrm{NCCS}_{2}$} & 1 & & 17914,2 & 450000 & 25,12 \\
\hline & 2 & & 17638,96 & 440000 & 24,94 \\
\hline & 3 & & 18100,86 & 300000 & 16,57 \\
\hline \multirow{4}{*}{$\mathrm{NCCS}_{2}$} & 1 & & 17745,02 & 450000 & 25,36 \\
\hline & 2 & & 18280,11 & 465000 & 25,44 \\
\hline & 3 & Topping & 17875,09 & 400000 & 22,38 \\
\hline & rerata & & & & 24,39 \\
\hline \multirow[t]{4}{*}{$\mathrm{NCCS}_{2}$} & 1 & & 18100,86 & 600000 & 33,15 \\
\hline & 2 & & 18094,9 & 520000 & 28,74 \\
\hline & 3 & & 17792,26 & 550000 & 30,91 \\
\hline & rerata & & & & 30,93 \\
\hline
\end{tabular}

Keterangan:

$\mathrm{NCCS}_{2} \quad$ : Normal Concrete Cylinder Substrate, dengan kuat tekan rencana $20 \mathrm{Mpa}$

$\mathrm{NCCT}_{2} \quad$ : Normal Concrete Cylinder Topping, dengan kuat tekan rencana $20 \mathrm{Mpa}$

$\mathrm{NCCT}_{2} \quad$ : Normal Concrete Cylinder Topping, dengan kuat tekan rencana $25 \mathrm{Mpa}$

$\mathrm{NCCT}_{3} \quad$ : Normal Concrete Cylinder Topping, dengan kuat tekan rencana $30 \mathrm{MPa}$

Hasil uji kuat tekan pada sampel NCCS201, NCCS-20-2 dan NCCS20-3 nilai yang didapat ialah 18,05 MPa, 16,65 MPa dan $20,82 \mathrm{MPa}$. Nilai rata-rata hasil uji kuat tekan pada sampel beton substrate 18,51 $\mathrm{MPa}$.

Dari hasil kajian yang telah dilakukan didapatkan nilai kuat tekan umur 28 hari untuk sampel beton bagian topping. Hasil yang disajikan di atas diketahui nilai ratarata sampel dengan notasi NCCT20, NCCT25, dan NCCT30 ialah 22,21 MPa, 24,39 MPa dan 30,93 MPa. Dengan hasil nilai yang diperoleh dapat dikategorikan masing-masing spesimen berdasarkan kuat tekan lapis substrate dan topping sebagai berikut:

Tabel 8. Kuat Tekan Beton Substrate dan Topping dengan masing-masing Notasi

\begin{tabular}{ccc}
\hline Spesimen & Lapis & Kuat tekan (Mpa) \\
\hline NCST20-20 & Substrate & 18,51 \\
& Topping & 22,21 \\
NCST20-25 & Substrate & 18,51 \\
& Topping & 24,39 \\
NCST20-25 & Substrate & 18,51 \\
& Topping & 30,93 \\
\hline
\end{tabular}

Beton silinder dengan kuat tekan rencana pada sampel beton substrate memilki nilai kuat tekan 18,15 MPa dengan kuat tekan rencana $20 \mathrm{MPa}$, sementara untuk sampel beton topping yaitu 22,21 $\mathrm{MPa}$ dengan kuat tekan rencana $20 \mathrm{MPa}$. Beton silinder dengan kuat tekan renacana pada sampel beton substrate memilki nilai kuat tekan $18,15 \mathrm{MPa}$ dengan kuat tekan rencana $20 \mathrm{MPa}$, sementara untuk sampel beton topping yaitu 24,39 $\mathrm{MPa}$ dengan kuat tekan rencana $25 \mathrm{MPa}$. Beton silinder dengan kuat tekan renacana pada sampel beton substrate memilki nilai kuat tekan $18,15 \mathrm{MPa}$ dengan kuat tekan rencana 20 $\mathrm{MPa}$, sementara untuk sampel beton topping yaitu $30,93 \mathrm{MPa}$ dengan kuat tekan rencana $30 \mathrm{MPa}$. 
Uji Eksperimental Geser ... (Indah/ hal 180-195)

Pengujian kuat geser dilakukan terhadap benda uji beton kubus dengan ketebalan beton substrate $12,5 \mathrm{~cm}$, sementara untuk topping ketebalannya yaitu $7,5 \mathrm{~cm}$. Pengujian kuat geser dilakukan apabila umur beton 56 hari, dihitung dari pengecoran substrate.

Perhitungan nilai kuat geser pada beton kubus memiliki dimensi keseluruhan $200 \mathrm{x}$ 200 x $200 \mathrm{~mm}$. Beton kubus dalam kajian merupakan beton normal dengan gabungan dari substrate dan topping dengan jarak waktu pengecoran antar beton 28 hari. Pada beton substarte memiliki ketebalan $125 \mathrm{~mm}$, sementara untuk topping memiliki ketebalan $75 \mathrm{~mm}$. Dalam pengujian kuat geser alat yang digunakan yaitu UTM (Universal Testing Machine), load cell, data logger, dan LVDT (Linier Variable Displacement Transducer). Dengan menggunakan alat tersebut akan menghasilkan pencapaian pembebanan dan nilai defleksi/deformasi. Kekuatan lekatan antar beton dapat dilihat dengan hasil yang didapat dari pengujian yang telah dilakukan, berikut hasil uji kuat geser menggunakan alat LVDT dan UTM serta pembahasan pada masing-masing sampel. Keterangan untuk masing-masing spesimen adalah sebagai berikut:

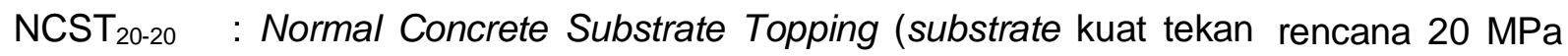
dan topping kuat tekan rencana $20 \mathrm{MPa}$ )

$\mathrm{NCST}_{20-25}$ : Normal Concrete Substrate Topping (substrate kuat tekan rencana $20 \mathrm{MPa}$ dan topping kuat tekan rencana $25 \mathrm{MPa}$ )

$\mathrm{NCST}_{20-230}$ : Normal Concrete Substrate Topping (substrate kuat tekan rencana $20 \mathrm{MPa}$ dan topping kuat tekan rencana $30 \mathrm{MPa}$ )

Tabel 9. Nilai Uji Kuat Geser NCST20-20

\begin{tabular}{cccccc}
\hline Spesimen & Berat $(\mathrm{kg})$ & $\begin{array}{c}\text { Luas Penampang } \\
\left(\mathrm{mm}^{2}\right)\end{array}$ & $\mathrm{P}$ Maks $(\mathrm{kN})$ & Kuat Geser (MPa) & Keterangan \\
\hline NCST $_{20-20-1}$ & 18,837 & 39228,4 & 18,724 & 0,48 & Gagal interface \\
NCST $_{20-20-2}$ & 19,074 & 39720,5 & 21,099 & 0,53 & Gagal interface \\
NCST $_{20-20-3}$ & 18,612 & 39657,6 & 12,599 & 0,32 & Gagal interface \\
NCST $_{20-20}$ & \multicolumn{5}{c}{ Kuat Geser Rata-rata } \\
\hline
\end{tabular}

Tabel di atas memiliki 3 (tiga) sampel beton kubus, dengan bagian substarte dan topping memiliki kuat tekan rencana yang sama yaitu $20 \mathrm{MPa}$. Hasil dari tabel diatas apabila digambarkan dengan grafik pembebanan dengan deformasi sebagai berikut: sampel NCST20-20-1 tingkat pembebanan mencapai 18,724 kN dan deformasi 510,468 mm, sampel NCST20-20-2 tingkat pembebanan mencapai 21,009 kN dan deformasi 520,38 $\mathrm{mm}$, untuk sampel NCST20-20-3 pembebanan maksimal yang dicapai $12,599 \mathrm{kN}$ dan deformasinya $411,438 \mathrm{~mm}$.

Tabel 10. Nilai Uji Kuat Geser NCST20-25

\begin{tabular}{cccccc}
\hline Spesimen & Berat $(\mathrm{kg})$ & $\begin{array}{c}\text { Luas Penampang } \\
\left(\mathrm{mm}^{2}\right)\end{array}$ & $\begin{array}{c}\text { P Maks } \\
(\mathrm{kN})\end{array}$ & Kuat Geser (MPa) & Keterangan \\
\hline NCST $_{20-25-1}$ & 18,972 & 40601,4 & 6,5991 & 0,16 & Gagal interface \\
NCST $_{20-25-2}$ & 19,161 & 41204,7 & - & - & Gagal setting \\
NCST $_{20-25-3}$ & 18,943 & 41195,5 & 30,474 & 0,74 & Gagal interface \\
NCST $_{20-20}$ & & Kuat Geser Rata-rata & & 0,45 & \\
\hline
\end{tabular}

Dalam pengujian ini hanya menggunakan 2 sampel karena 1 sampel yaitu NCST20-25-2 mengalami kegagalan setting. Data dari tabel diatas apabila digambarkan dengan profil grafik 
beton kubus yang diberi beban dan berhubungan langsung dengan deformasi adalah sebagai berikut: sampel NCST20-25-1 untuk pembebanan hanya mencapai 6,5991 kN dan nilai deformasinya yaitu 490,644 mm sedangkan sampel NCST20-25-3 memproleh angka pembebanan 30,474 kN dan deformasi yang dicapai yaitu 193,284 mm.

Tabel 11. Nilai Uji Kuat Geser NCST20-30

\begin{tabular}{cccccc}
\hline Spesimen & Berat $(\mathrm{kg})$ & $\begin{array}{c}\text { Luas Penampang } \\
\left(\mathrm{mm}^{2}\right)\end{array}$ & $\begin{array}{c}\mathrm{P} \\
\text { Maks }(\mathrm{kN})\end{array}$ & Kuat Geser (MPa) & Keterangan \\
\hline NCST $_{20-30-1}$ & 18,471 & 39678,2 & 18,724 & 0,38 & Gagal interface \\
NCST $_{20-30}-2$ & 18,322 & 40492,9 & 21,099 & 0,36 & Gagal interface \\
NCST $_{20-30-3}$ & 18,501 & 40606,4 & 12,599 & 0,16 & Gagal interface \\
NCST $_{20-30}$ & \multicolumn{3}{c}{ Kuat Geser Rata-rata } \\
\hline
\end{tabular}

Data di atas apabila digambarkan menggunakan profil grafik hubungan pembebanan dengan deformasi yang terjadi pada beton kubus adalah sebagai berikut: sampel NCST20-30-1 dalam pembebanan mencapai $14,974 \mathrm{kN}$ dan nilai deformasi yaitu 158,592 $\mathrm{mm}$, sampel NCST20-30-2 dalam pembebanan mencapai $14,599 \mathrm{kN}$ dan nilai deformasi yaitu $334,53 \mathrm{~mm}$, sedangkan sampel NCST20-30-3 dalam pembebanan mencapai $6,3492 \mathrm{kN}$ dan nilai deformasi yaitu 183,372 mm. Dari ketiga sampel tersebut untuk NCST20-30 didapat nilai kuat geser rerata yaitu $0,30 \mathrm{MPa}$.

Hasil dari pengujian yang telah dilakukan, didapat nilai kuat geser substrate dan topping dengan variasi kuat tekan rencana pada lapis topping. Nilai maksimal didapat pada beton normal dengan substrate 20 $\mathrm{MPa}$ dan topping $25 \mathrm{MPa}$ (NCST20-25) dengan nilai yang diperoleh adalah 0,45 MPa. Nilai yang didapat pada pada NCST20-20 yaitu 0,44 MPa, dan pada notasi NCST20-30 yaitu 0,30 MPa. Dengan diterapkannya variasi pada topping untuk mendapatkan perbandingan nilai kuat geser, dapat disimpulkan bahwa dengan semakin tinggi kuat tekan rencana pada beton topping akan menghasilkan kuat geser yang rendah.

Kondisi permukaan sambungan sangat menentukan nilai kuat geser, dengan salah satu cara meningkatkan nilai kuat geser yaitu mengkasarkan permukaan sambungan. Pada kajian ini kondisi permukaan sambungan tidak dikasarkan. Dari hasil yang didapat kuat geser maksimal yaitu 0,45 Mpa. Pada benda uji bagian permukaan sambungan dengan pengkasaran tingkat tinggi mendapatkan nilai kuat geser 4,72 $\mathrm{MPa}$ dan pengkasaran tingkat rendah 2,34 $\mathrm{MPa}$. Dari hasil kajian membuktikan dengan pengkasaran permukaan sambungan didapat kuat geser yang tinggi dibandingkan tanpa pengkasaran permukaan sambungan.

\section{SIMPULAN}

Berdasarkan hasil pengujian geser beton substrate ditambah beton topping dengan variasi kekuatan tekan rencana pada lapis topping, maka didapat kesimpulan sebagai berikut: (1) Kuat tekan rencana 20 $\mathrm{MPa}$ untuk sampel beton substrate didapat hasil kuat tekan rerata yaitu $18,51 \mathrm{MPa}$. Kuat tekan rencana $20 \mathrm{MPa}, 25 \mathrm{MPa}$, dan $30 \mathrm{MPa}$ untuk sampel beton topping didapat kuat tekan rerata yaitu 22,21 MPa, 24,39 MPa, dan 30,93 MPa. (2) Hasil uji geser sambungan beton substrate dan beton topping dengan notasi NCST20-20, NCST20-25, dan NCST20-30 didapat kuat geser rerata sebesar 0,44 MPa, 0,45 $\mathrm{MPa}$ dan 0,3 MPa. (3) Faktor yang memepengaruhi nilai kuat geser yaitu tekstur permukaan sambungan, proses hidrasi, fungsi agregat, faktor air semen, kuat tekan, nilai slump, porositas beton, dan kedap air. 
Uji Eksperimental Geser ... (Indah/ hal 180-195)

\section{DAFTAR RUJUKAN}

Aryanto, Tri. (2016). Uji Kinerja Interface Beton Lama (Substrate) dan Beton Baru (Overlay) Dengan Variasi Kuat Tekan Substrate.

Badan Standardisasi Nasional (2000). Tata Cara Pembuatan Campuran Beton Normal. SNI 03-2834-2000. Jakarta: Departemen Pekerjaan Umum.

Badan Standardisasi Nasional (2008). Tata Cara Pembuatan Kaping untuk Benda Uji Silinder Beton. SNI 63692008:11. Jakarta: Departemen Pekerjaan Umum.

Badan Standardisasi Nasional. (2002). Spesifikasi Agregat Halus untuk Pekerjaan Adukan dan Plesteran dengan Bahan Dasar Semen. SNI 02-6820-2002. Jakarta: Departemen Pekerjaan Umum.

Ilsay, LH. (1942). American Highway Practice. Vol. II, Fourth Printing. New York: Jhon Wiley \& Son Incorporation.

Momayez, A., dkk. (2005). Compaparison of Methods or Evaluating Bond Strength Between Concrete Substrate and Repair Materials. IJE Vol. 15, No.4, December 2002-319.

Mulyono, Tri. (2005). Teknologi Beton. Yogyakarta: Andi.

Prihadi, W. R., \& Pratama, G. N. I. P. Konfigurasi Batang Pada Perancangan Rangka Atap Bambu. INERSIA, 12(2), 173-183.

Samekto, W. \& Rahmadiyanto, C. (2001). Teknologi Beton. Yogyakarta: Kanisius.

Santos, PMD. \& Julio, ENBS. (2009). FTUC Depatemento de Engenharia Civil. Assessment of the Shear Strength Between Concrete Layers.
Sukrawa, Made., Sudarsana, IK., \& Dana, W. (2011). Perkuatan Pelat Jembatan Dek Baja dengan Overlay Beton Bertulang. Jurnal Teknik Sipil Vol. 18. No. 3. Desember.

Sutapa, A.A. Gede. (2011). Porositas, Kuat Tekan, dan Kuat Tarik Belah Beton dengan Agregat Kasar Batu Pecah Pasca Dibakar. Jurnal IImiah Teknik Sipil Vol. 15, No. 1, Denpasar Januari 2011.

Tjokrodimuljo, K. (2007). Teknologi Beton. Yogyakarta: Biro Penerbit KMTS FT UGM.

Viel, Rionald. (2013). Kuat Geser Mortar Joint Beton Ringan Aerasi (Autocalaved Aerated Concrete) Tipe Powerblock dengan Menggunakan Thin Bed Mortar. 